\title{
A Formação de Representações Sociais de Transgênicos: a Importância da Exposição Científica ${ }^{1}$
}

\author{
Juliana Mezzomo Allain² \\ Clélia Maria Nascimento-Schulze \\ Universidade Federal de Santa Catarina
}

\begin{abstract}
RESUMO - Os transgênicos têm sido frequentemente apontados como um exemplo na discussão da relação entre ciência, tecnologia e sociedade. Muitos países, incluindo o Brasil, têm apostado na atividade da divulgação científica para auxiliar a se pensar essa relação. A teoria das representações sociais pertence a uma tradição que estuda a divulgação científica desde a década de 60 do século XX. Esta pesquisa teve como objetivo verificar o impacto de uma exposição científica sobre transgênicos nas representações sociais desse objeto de alunos do Ensino Médio de uma escola pública de Florianópolis. Os resultados mostram que a exposição científica pode ajudar na formação de representações úteis ao processo de reflexão sobre a relação entre ciência e sociedade.
\end{abstract}

Palavras-chave: representações sociais; transgênicos; exposição científica.

\section{The Formation of Transgenic's Social Representations: The Importance of a Scientific Exhibition}

\begin{abstract}
Transgenic have been often pointed out as an example whenever the relation between science, technology and society is discussed. Many countries, including Brazil, have bet on the activity of scientific diffusion in order to help rethinking this relation. The theory of social representations belongs to a tradition that studies scientific diffusion since the sixties of the twentieth century. The present research's goal was to verify the impact of a scientific exhibition about transgenic on the social representations of this object among high school students from Florianopolis. The results show that scientific exhibition can help forming representations that are useful in the reflection process about the relation between science and society.
\end{abstract}

Keywords: social representations; transgenic; scientific exhibition.

No trabalho intitulado Livro Verde. Ciência, tecnologia e inovação: desafio para a sociedade brasileira (Silva \& Melo, 2001), o governo brasileiro apresenta alguns desafios para os quais a sociedade brasileira precisa buscar soluções no curto prazo, mas também assegurando maior qualidade de vida para as gerações futuras. Dentre esses desafios, o documento destaca os novos organismos transgênicos ${ }^{3}$. Para auxiliar a população a enfrentar tais desafios, o livro também dá uma atenção especial à atividade da divulgação científica.

De fato, os transgênicos têm sido frequentemente tomados como um exemplo na discussão sobre a relação entre ciência, tecnologia e sociedade. A Declaração Universal sobre o Genoma Humano e os Direitos Humanos, adotada

1 Agradecemos à CAPES pela concessão de uma bolsa de estudos.

2 Endereço para correspondência: Av. Engenheiro Mesquita, 715/503, Centro. Araranguá, SC. CEP 88900-000. Telefone: (48) 3521-0457/ (48) 9124-2192. E-mail: jumezzomo@hotmail.com.

3 A definição legal no Brasil de um organismo geneticamente modificado é aquele organismo cujo material genético (ácidos desoxirribonucléico - ADN, e ribonucléico - ARN) tenha sido modificado por qualquer técnica de engenharia genética, definida como atividade de produção e manipulação de moléculas ADN/ARN recombinante - manipuladas fora das células vivas, mediante a modificação de segmentos de ADN/ ARN natural ou sintético que possam multiplicar-se em uma célula viva, ou ainda as moléculas de ADN/ARN resultantes dessa multiplicação, considerados os segmentos de ADN/ARN sintéticos equivalentes aos de ADN/ARN natural (art. $3^{\circ}$, incisos III, IV e V da Lei 11.105/2005) (Brasil, 2005). pela Conferência Geral da UNESCO em sua $29^{\circ}$ sessão em 1997, estabeleceu diretrizes para se enriquecer o debate público sobre temas como os transgênicos, envolvendo todos os membros da sociedade. Essas diretrizes identificavam as tarefas que caberiam a diferentes atores na implementação da Declaração e também as modalidades de ações para se efetivar sua concretização. Entre essas modalidades, destaca-se realizar exibições multimídia, especialmente para jovens.

\section{Divulgação Científica}

A divulgação científica, por meio de um processo de recodificação (transposição de uma linguagem especializada para uma linguagem não especializada), busca tornar o conteúdo científico acessível a uma vasta audiência (Bueno, 1985). Mas, como tais atividades de divulgação científica podem auxiliar a população a enfrentar os novos desafios que a ciência e a tecnologia nos apresentam?

Muitas vezes, a divulgação científica é concebida dentro do modelo do esclarecimento ou do déficit científico (Irwin \& Wynne, 1996). Nesse modelo, o conhecimento científico é universal, objetivo e livre de valor, os cientistas são os únicos detentores do saber relacionados à ciência e tecnologia e seu papel é de esclarecer o público que é visto como homogêneo e ignorante. O medo ou resistência do público 
frente a uma nova tecnologia é visto como irracional ou sem fundamento.

Porém, Jurdant (1975) propõe um outro objetivo para essa atividade. Para esse autor, o objetivo da divulgação científica não é formar especialistas, mas assegurar a presença da ciência na cultura geral das pessoas, a fim de que estas possam compreender melhor seu ambiente cotidiano. A divulgação científica seria responsável não somente por esclarecer o público sobre os processos e descobertas científicas, mas também por denunciar os impactos econômicos, sociais e ambientais das mesmas.

Segundo Roqueplo (1974), a divulgação científica não permite, efetivamente, uma partilha do saber científico. $\mathrm{O}$ autor argumenta, então, que a divulgação científica "contribui a dar à ciência a única modalidade cultural que lhe é possível fora do mundo científico propriamente dito, a saber: o estatuto de representação social” (p. 136). Assim, a função da divulgação científica, para esse autor, seria a de formar, ou modificar, as representações sociais do cidadão comum. Nesse sentido, os divulgadores científicos seriam "mais criadores do que tradutores" (p. 150).

\section{Representações Sociais}

Segundo Moscovici (1978), a ciência e a tecnologia "inventam e propõem a maior parte dos objetos, conceitos, analogias e formas lógicas a que recorremos para fazer face às nossas tarefas econômicas, políticas ou intelectuais” (pp. 20-21). Mais que isso, segundo esse autor, o que entendemos, percebemos e representamos como dado imediato de nossos sentidos é um produto re-elaborado das pesquisas científicas. Assim, Moscovici atribui uma grande importância à divulgação científica para a formação das representações sociais. De fato, a teoria das representações sociais se interessa em como um novo conhecimento científico se espalha e é apropriado por diferentes grupos sociais, pertencendo a uma tradição que estuda a divulgação da ciência desde os anos 60 do século XX (Bauer, 2003).

Jodelet (2001) define as representações sociais como "uma forma de conhecimento, socialmente elaborada e partilhada, com um objetivo prático, e que contribui para a construção de uma realidade comum a um conjunto social” (p. 22). As representações sociais nos ajudam a dominar o nosso ambiente, compreender e explicar os fatos e ideias que preenchem o nosso universo, situar-nos a seu respeito, responder às questões que o mundo nos coloca e saber o que as descobertas da ciência e o devir histórico significam (Jodelet, 1986).

\section{Divulgação Científica e a Formação/ Transformação das Representações Sociais}

O Laboratório de Psicossociologia da Comunicação e Cognição Social (LACCOS) da Universidade Federal de Santa Catarina vem consolidando uma linha de pesquisa que envolve o estudo de interações, representações sociais e atitudes num contexto de exposições científicas sobre o meio ambiente (Carboni, 2005; Martinelli, 2006; Mezzomo
\& Nascimento-Schulze, 2004; Nascimento-Schulze, 2007; Nunes, 2005). A maioria dessas pesquisas têm se pautado na abordagem estrutural das representações sociais, uma vez que ela permite um estudo comparativo das representações (Abric, 1998).

Segundo a abordagem estrutural, os elementos de uma representação (informações, crenças, opiniões e atitudes) são hierarquizados e se organizam em torno de um núcleo central. Esse núcleo é o que dá significado à representação, e em torno dele se organizam os elementos periféricos. Em um estudo experimental, a identificação dos elementos centrais e periféricos, antes e depois, permite ver as transformações pelas quais a representação passou.

Para falarmos de transformações das representações, fazse necessário explicar a noção de reversibilidade da situação introduzida por Flament (2001). Segundo essa noção, os indivíduos engajados em uma situação, e nela desempenhando certas práticas, podem considerar tal situação como irreversível, sendo o retorno a práticas anteriores impossível. Ou eles podem considerar tal situação como reversível, uma vez que é vista como temporária, sendo o retorno a práticas anteriores possível. Dependendo da percepção da situação pelos sujeitos, as transformações serão diferentes.

Se a situação é percebida como reversível, novas práticas desencadeiam mudanças por meio de novos elementos que se integram aos elementos periféricos, mas o núcleo central se mantém estável, sendo uma modificação superficial da representação. No entanto, se a situação é percebida como irreversível, novas práticas, contraditórias com a situação anterior, desencadearão uma mudança significativa nas representações, podendo ocorrer três tipos de transformação, segundo Abric (1998):

1) Transformação resistente - quando o sistema periférico pode gerenciar práticas novas e contraditórias por meio de mecanismos de defesa, tais como: interpretação e justificação ad hoc, racionalizações, referências a normas externas à representação. Nesse caso, a transformação da representação se caracterizará então pelo aparecimento de esquemas estranhos no sistema periférico;

2) Transformação progressiva da representação quando práticas novas não são completamente contraditórias com o núcleo central. Nesse caso, a transformação da representação se dá sem ruptura do núcleo central, uma vez que os esquemas ativados pelas práticas novas se integram aos esquemas do núcleo central, construindo uma nova representação;

3) Transformação brutal - quando o sistema periférico não pode gerenciar novas práticas por meio dos mecanismos de defesa, uma vez que elas atacam diretamente o significado central da representação e têm caráter irreversível. Nesse caso, há uma ruptura do núcleo central provocando uma transformação completa da representação.

De maneira geral, os resultados das pesquisas realizadas no LACCOS mostram que as exposições científicas têm um impacto sobre as representações sociais do meio ambiente 
por meio do surgimento de esquemas estranhos no sistema periférico das representações, os quais faziam referência ao conteúdo da exposição científica. Além disso, os resultados mostram que, mais do que contribuir para a mera aquisição de informações científicas, as exposições científicas sobre meio ambiente têm contribuído para dar lugar a reflexões que incluam essas informações.

O primeiro desses estudos (Mezzomo \& NascimentoSchulze, 2004), realizado com alunos do Ensino Médio, utilizou como setting uma exposição científica baseada na noção de dois paradigmas de meio ambiente (Paradigma Social Dominante e Novo Paradigma Ambiental). A exposição foi construída de forma a explicitar o contraste entre o homem como excluído ou como parte integrante do meio ambiente. A exposição utilizou três mídias diferentes e os alunos passaram por três etapas: (1) uma sessão composta por banners contendo informações acerca da exposição e dos dois paradigmas e fotos que representavam os dois paradigmas; (2) uma sessão de vídeo, na qual a ideia dos paradigmas ambientais era mais bem aprofundada e a questão da intervenção na natureza era discutida por experts nas áreas de pesquisa sobre transgênicos; e (3) uma sessão interativa por meio de um sítio eletrônico, que era acessado em computadores no local. Os alunos podiam explorar tanto os conteúdos de toda a exposição como também responder a um questionário de atitudes frente aos paradigmas ambientais. Entre os assuntos abordados na exposição, os transgênicos foram os que mais despertaram interesse nos alunos.

\section{O Campo de Pesquisas sobre Transgênicos}

O campo de pesquisas sobre percepção pública de transgênicos no cenário internacional é vasto. Em 2005, a Revista d'etnologia de Catalunya também publicou uma edição dedicada à percepção da biotecnologia aplicada à alimentação, apresentando, além dos artigos, uma seleção bibliográfica que apontou mais de 200 pesquisas sobre esse tema no cenário internacional. Muitas pesquisas vêm sendo publicadas nas revistas das mais diversas áreas - psicologia, sociologia, economia, política -, mostrando a complexidade e pluralidade de pontos de vista sobre o assunto. Essa pluralidade também resulta em uma diversidade de enfoques e abordagens, incluindo pesquisas sobre representações sociais de transgênicos (consultar, por exemplo, a obra de Bauer \& Gaskell, 2002).

Nos últimos anos, os transgênicos começaram a despertar a atenção dos pesquisadores brasileiros. No entanto, grande parte das pesquisas envolvendo essa questão está limitada à análise do processo de regulamentação (Labarrère, 2000; Lazzarini, 2000; Porto, 2005) e dos atores envolvidos nesse processo (Guivant, 2002, 2005). Já o cenário de pesquisas sobre a percepção pública de transgênicos no Brasil é muito limitado, contrastando com o cenário internacional. Entre as poucas pesquisas nacionais sobre o conhecimento e opiniões a respeito dos transgênicos, pode-se citar três, realizadas pelo Instituto Brasileiro de Opinião Pública e Estatística (IBOPE, 2001, 2002, 2003), sob encomenda do Greenpeace.

Os resultados da pesquisa de 2003 mostraram que os homens já ouviram falar mais sobre transgênicos do que as mulheres. A faixa de idade parece não diferenciar a proporção do conhecimento ${ }^{3}$ da população sobre o assunto. $\mathrm{O}$ grau de instrução pesa bastante, aumentando o conhecimento junto com o grau de instrução. A população da região sul é a que mais ouviu falar sobre transgênicos, enquanto mais da metade da população da região nordeste nunca ouviu falar sobre o assunto. E o critério econômico foi o que mais influenciou, sendo que quase a totalidade das classes A e B já ouviram falar sobre transgênicos e quase metade das classes D e E nunca ouviram falar sobre o assunto.

Nessa pesquisa, o participante era informado sobre o que é um organismo transgênico. Depois, era perguntado se caso ele pudesse escolher entre um alimento transgênico e um alimento não-transgênico, qual ele escolheria. Entre 70-80\% dos entrevistados escolheriam alimentos não-transgênicos e entre $10-15 \%$ escolheriam alimentos transgênicos. Além disso, $70-80 \%$ dos participantes responderam que os transgênicos deveriam ser proibidos e $10-20 \%$ responderam que eles deveriam ser liberados.

No entanto, a empresa Monsanto também encomendou uma pesquisa sobre percepção pública de transgênicos ao IBOPE, que utilizou uma metodologia diferente da encomendada pelo Greenpeace, sendo obtidos resultados divergentes. Isto é, a pesquisa encomendada pela Monsanto encontrou uma aceitação muito maior dos transgênicos pela população. Segundo Guivant (2006), a divergência entre os resultados de pesquisas encomendadas ocorrem porque as mesmas apenas confirmam os argumentos que determinados grupos sociais, políticos ou econômicos, que encomendam as pesquisas, querem legitimar. A autora argumenta que a falta de pesquisas sobre percepção pública de transgênicos, ou seu número limitadíssimo, revela o caráter do debate no país, os limites da área de pesquisa e a "falta de problematização no espaço acadêmico sobre os conflitos ou consensos entre conhecimentos peritos e leigos quando estão em questão inovações tecnológicas que envolvem riscos” (p. 82).

Além disso, alguns resultados encontrados em outras pesquisas, tais como o desconhecimento, a indiferença ou resignação da população frente aos riscos alimentares (Guivant, 2002; Silva \& Amaral, 2004), levam a um questionamento sobre a existência de uma representação social formada sobre os transgênicos na população estudada.

Salesses (2005) destaca que, geralmente, as pesquisas sobre representações sociais trabalham com representações já constituídas e que é raro encontrar estudos que se interessem pelo que precede a elaboração da representação. Essa autora argumenta que a abordagem estrutural permite evidenciar a estrutura tanto de uma representação já constituída, como a de uma em vias de construção.

Nos estudos sobre impacto de exposições científicas na transformação das representações sociais de meio ambiente, citadas anteriormentes, podia-se trabalhar com a hipótese de transformação da representação social porque se sabia que os grupos estudados possuíam uma representação social formada sobre meio ambiente. No presente estudo, não se sabia se o mesmo ocorria com os transgênicos. Assim, neste estudo, trabalhou-se com as hipóteses de formação/transformação

3 Conhecimento, nessa pesquisa, limitava-se à pessoa ter ouvido ou não falar sobre transgênicos. 
da estrutura das representações sociais de transgênicos a partir de uma exposição científica. Mais especificamente, o objetivo deste trabalho foi de verificar o impacto da visita a uma exposição científica sobre transgênicos na formação das representações sociais deste objeto social por alunos do Ensino Médio de uma escola pública da cidade de Florianópolis.

\section{Método}

\section{Participantes}

Participaram deste estudo 120 alunos do Ensino Médio de uma escola pública de Florianópolis. Entre os participantes, 77 eram do sexo feminino e 43 do sexo masculino. A média de idade dos participantes foi de 16,23 anos (variando entre 14 a 19 anos). Os alunos estudavam no período diurno. Não foi feita uma coleta prévia sobre o nível de informação e interesse dos alunos em relação aos transgênicos, mas sabia-se que esse assunto ainda não havia sido estudado em sala de aula.

\section{Procedimento}

Em 2005, a OCIP (Organização da Sociedade Civil de Interesse Público) desenvolveu uma exposição científica sobre transgênicos para as comemorações da Semana Nacional de Ciência e Tecnologia, organizada pelo Ministério da Ciência e Tecnologia. Essa exposição foi utilizada como setting de estudos para a presente pesquisa. A exposição científica era composta por oito banners que traziam informações balanceadas sobre os transgênicos (considerando os aspectos científicos, econômicos, ambientais, sociais e jurídicos: 1 - uma introdução sobre a exposição; 2 - uma citação de Eduardo Portella, da UNESCO, sobre ética e ciência; 3 uma explicação sobre o que é biotecnologia (em específico, a engenharia genética); 4 - informação acerca dos processos para se criar plantas transgênicas; 5 - posicionamentos (argumentos contra e a favor) em relação aos transgênicos e informações sobre o princípio de precaução; 6 - a legislação (mundial, nacional e estadual) sobre os transgênicos; 7 - sites onde buscar mais informações; 8 - um banner dos créditos de realização da exposição.

O procedimento compreendeu três condições experimentais: na primeira, a coleta de dados foi realizada na própria escola, antes da visita dos alunos à exposição científica sobre transgênicos; na segunda, a coleta ocorreu logo após a visita à exposição, em uma sala ao lado da mesma; e na terceira, a coleta foi efetuada novamente na escola, um mês depois da visita à exposição. A terceira coleta foi feita para verificar se as possíveis transformações nas representações se mantinham. No entanto, não foi feito um controle em relação às novas informações que os alunos buscaram ou receberam sobre transgênicos durante o período entre a segunda e a terceira coleta de dados (sabe-se que os professores deveriam explicar o tema em sala de aula e que alguns pediriam um trabalho de pesquisa sobre o tema).
Em cada uma das três condições foi utilizada uma técnica de evocação para coletar os dados, por meio da qual era pedido aos alunos que escrevessem, individualmente, as cinco primeiras palavras que lhes viessem à mente a partir do termo indutor: TRANSGÊNICOS.

\section{Análise de dados}

Os dados foram analisados com a ajuda do programa EVOC (Ensemble de Programmes Permettant l'Analyse des Évocations) (Vergès, 1999). Tal programa faz uma análise lexicográfica que permite a análise da estrutura das representações sociais, levantando seus elementos centrais e periféricos por meio da hierarquização dos itens evocados, considerando tanto a frequência como a ordem de evocação das palavras (Nascimento-Schulze \& Camargo, 2000).

\section{Resultados}

O número total de evocações produzidas pelos alunos variou muito pouco de uma condição para outra ( $N=589$ na primeira, $\mathrm{N}=598$ na segunda e $\mathrm{N}=588$ na terceira). Porém, o número de palavras diferentes produzidas pelos mesmos na primeira condição $(\mathrm{N}=201)$ diminuiu consideravelmente na segunda $(\mathrm{N}=172)$ e um pouco mais na terceira $(\mathrm{N}=166)$. Isso pode significar que alguns elementos evocados pelos alunos passaram a ser mais compartilhados pelo grupo, em detrimento de outros elementos que eram mais idiossincráticos e menos apropriados ou corretos.

A partir das respostas dos alunos nas três condições experimentais, foram produzidos três conjuntos de dados, apresentados em diagramas com quatro quadrantes, que levaram em conta dois critérios: frequência do item evocado e ordem média de evocação (ver Quadro 1).

No primeiro quadrante da condição "antes da visita à exposição científica", destacaram-se dois elementos: alimentos e remédios. Trata-se dos elementos com possibilidade de serem centrais. O sistema periférico dessa condição é constituído por elementos que remetem às palavras do primeiro quadrante (alimentos: soja, frutas, verduras, comida, sementes, alimentação; remédios: saúde, doença, produtos, genéricos, drogas, prevenção). Além disso, aparecem outros elementos referentes ao processo científico pelos quais esses alimentos e remédios são produzidos: genética, laboratório, modificado, genes, artificial, mudança, ciência, modificação, transformação e DNA.

Os alunos, nessa condição, consideraram a aplicação dos transgênicos principalmente no campo alimentar e, em menor proporção, no da saúde. As evocações se restringiram somente aos produtos e processos pelos quais são obtidos os transgênicos, sem emitir julgamentos, nem considerar as possíveis consequências que os transgênicos podem trazer. Pode-se pensar que a estrutura da representação social desse grupo se traduz na seguinte frase: Transgênicos são alimentos e remédios artificiais, que foram geneticamente modificados pela ciência em laboratórios.

O primeiro quadrante dos alunos na condição "logo após a visita à exposição científica" é composto por três elemen- 


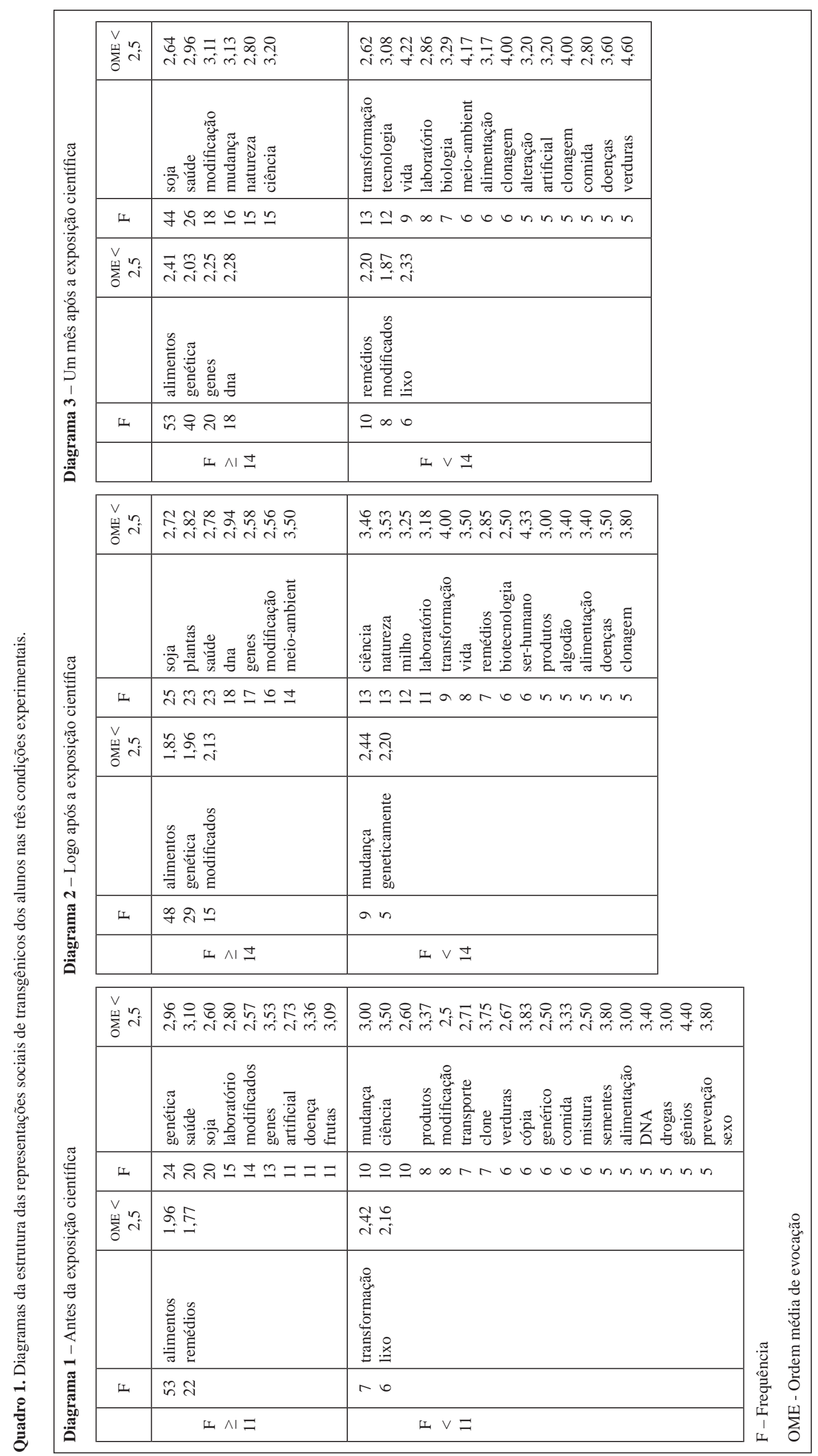


tos: alimentos, genética e modificados. A palavra alimentos ainda apresenta uma frequência bastante alta, embora esta tenha diminuído um pouco em relação à situação anterior. As palavras genética e modificados, que antes apareciam no segundo quadrante, passam nessa condição para o primeiro quadrante. Isso pode indicar que os alunos passaram a dar mais importância ao processo pelo qual os transgênicos são produzidos.

O sistema periférico dessa condição é constituído, em parte, por elementos que remetem às palavras do primeiro quadrante (alimentos: soja, milho, alimentação; genética: DNA, genes, geneticamente, biotecnologia; modificados: modificação, transformação, mudança). Porém, observa-se, também no sistema periférico, o surgimento de uma série de palavras que não apareciam na estrutura desse grupo na condição anterior e que fazem referência à exposição pela qual os alunos haviam passado: plantas e meio ambiente (no segundo quadrante), natureza, milho, vida, biotecnologia, ser humano e algodão (no quarto quadrante).

É importante destacar que a palavra remédios, que antes estava no primeiro quadrante (com frequência alta e baixa ordem média de evocação), passa para o quarto quadrante nessa segunda condição e apresenta uma diminuição considerável da sua frequência, bem como um aumento da ordem média de evocação. Igualmente, a palavra doenças, que estava no segundo quadrante na condição anterior, passa para o quarto quadrante, também com uma diminuição de sua frequência. Apesar disso, a palavra saúde se mantém no segundo quadrante, apresentando um pequeno aumento da sua frequência, assim como uma diminuição da ordem média de evocação. Uma possível explicação para isso pode ser relacionada ao conteúdo da exposição científica. A exposição trazia informações sobre os possíveis riscos que os transgênicos poderiam trazer para a saúde humana, para o meio ambiente e para a sociedade. Por outro lado, o conteúdo da exposição científica focalizou a aplicação dos transgênicos na agricultura e não no campo da saúde. Isso pode explicar a manutenção da importância dada pelos alunos à questão da saúde e a diminuição da importância dada aos remédios.

A estrutura das representações sociais de transgênicos dos alunos na segunda condição mostra que estes continuam a considerar os transgênicos, principalmente, como alimentos geneticamente modificados. Mas os novos elementos que surgiram no sistema periférico levam a pensar que os alunos passaram a considerar também os possíveis riscos que os transgênicos podem trazer para o meio ambiente, para o homem e para a vida em geral.

O primeiro quadrante dos alunos na condição "um mês após a visita à exposição científica" é composto por quatro elementos: alimentos, genética, genes e dna. A palavra alimentos, presente nesse quadrante nas três condições, volta a apresentar a mesma frequência em relação à primeira condição.

A palavra genética não mudou de quadrante em relação à segunda condição, mas apresenta um aumento considerável na sua frequência. Além disso, as palavras genes e DNA que estavam no segundo quadrante, na segunda condição, passaram agora para o primeiro quadrante, apresentando também um pequeno aumento nas suas frequências. Seguindo a tendência apontada pela condição anterior, isso pode indicar que os alunos passaram a dar cada vez mais importância ao processo pelo qual os transgênicos são produzidos. Outro aspecto importante relacionado a esse processo diz respeito à presença da palavra ciência, que passa do quarto quadrante (nas duas condições anteriores) para o segundo quadrante. Além disso, nessa última condição surge, no quarto quadrante, a palavra tecnologia, que não estava presente em nenhum quadrante nas condições anteriores, e que pode estar igualmente relacionada ao processo de produção dos transgênicos, enfatizando a importância dada pelos estudantes a esse aspecto.

Mais uma vez, pode-se notar que o sistema periférico desse grupo é constituído, em parte, por elementos que remetem às palavras do primeiro quadrante (alimentos: soja, alimentação, comida, verduras). A palavra remédios aparece, nessa condição, no terceiro quadrante e com uma frequência ainda muito menor do que a apresentada na primeira condição.

Observa-se também que alguns elementos que haviam surgido no sistema periférico desse grupo depois de ter visitado a exposição, e possivelmente ativados por esta, desaparecem na última condição, tais como: plantas, milho, biotecnologia, ser humano e algodão. Entretanto, outros desses elementos continuam presentes: natureza (que se mantém no segundo quadrante e apresenta um pequeno aumento na sua frequência), meio ambiente (que passa do segundo para o quarto quadrante, apresentando tanto uma diminuição considerável na sua frequência, quanto um aumento da ordem média de evocação) e vida (que se mantém no quarto quadrante).

A estrutura encontrada na terceira condição mostra que os alunos continuaram a considerar os transgênicos, principalmente, como alimentos geneticamente modificados. Os elementos que surgiram no sistema periférico depois da visita e que permaneceram nessa condição levam a pensar que os alunos continuaram a considerar também os possíveis riscos que os transgênicos podem trazer para o meio ambiente e para a vida.

Comparando as três estruturas, pode-se notar que houve um aumento do número de palavras que compõem o primeiro quadrante. Além disso, a frequência total dessas palavras aumenta consideravelmente de uma condição para outra, o que significa que estas passam a ser mais compartilhadas pelos alunos. Antes da visita, o primeiro quadrante era composto por duas palavras: alimentos e remédios, evocadas 75 vezes. Depois da visita, esse quadrante é formado por três palavras: alimentos, genética e modificados, evocadas 92 vezes. Por último, o primeiro quadrante da condição "um mês após a visita” é composto por quatro palavras: alimentos, genética, genes e DNA, evocadas 131 vezes.

Ainda assim, pode-se pensar que a estrutura das representações sociais desse grupo de alunos evoluiu na direção já apontada pela análise da primeira condição: os alunos priorizaram os produtos (alimentos, principalmente, mas também remédios) e o processo científico (modificação genética) pelos quais são obtidos os transgênicos. Por outro lado, os novos elementos que surgiram no sistema periférico desse grupo nas condições posteriores podem indicar que a visita à exposição científica levou os alunos a considerar também os possíveis riscos dos transgênicos. 
Na análise lexicográfica, apresentada acima, foi utilizada uma pequena percentagem tanto do número de palavras diferentes, assim como do total de evocações (em média, 58\%), em todas as condições experimentais. A presença de muitas palavras diferentes (com frequência menor que 5), porém com um significado próximo, pode ter levado à não consideração de aspectos importantes da representação social desses alunos. Assim, foi feito um reagrupamento das evocações. É preciso ressaltar que não se trata de uma categorização propriamente dita, mas apenas de um reagrupamento por proximidade de significado. $O$ Quadro 2 apresenta a frequência dos conjuntos de palavras considerados (com frequência igual ou maior que 5) para as três condições.
Após o reagrupamento das evocações, foram considerados um número muito maior de palavras diferentes, assim como do total de evocações (em média, 80\%). Além disso, pode-se notar o surgimento de outros aspectos na representação social de transgênicos nas três condições experimentais. Assim, serão feitas comparações entre: 1 - os conjuntos de evocações e a estrutura da representação social descrita anteriormente, correspondentes a cada condição; e 2 - os conjuntos de evocações presentes nas três condições.

A análise do reagrupamento das evocações referente à condição "antes da visita à exposição científica" mostrou que os alimentos e remédios, assim como o processo pelos quais eles são produzidos (modificação, biotecnologia, pesquisa,

Quadro 2. Frequência dos conjuntos de palavras associadas às três condições experimentais.

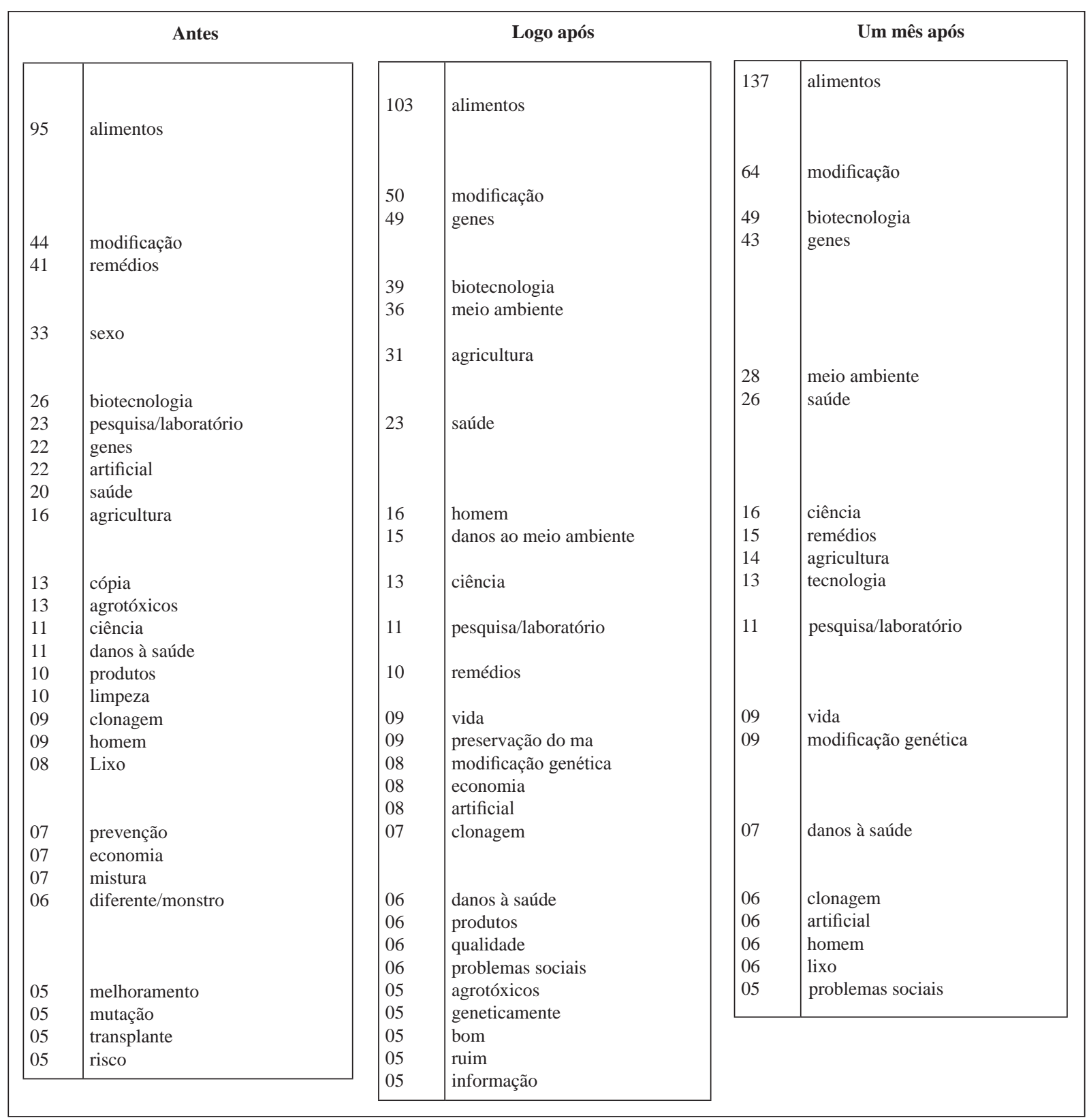


genes, ciência), continuam sendo muito importante. Surgem outros aspectos ligados à questão alimentar, tais como agricultura e agrotóxicos, assim como outros referentes à aplicação dos transgênicos no campo da saúde, tais como danos à saúde e transplante.

Evidencia-se a ênfase dada ao elemento sexo enquanto associado ao tópico. Isso pode ser explicado pelo fato dos alunos terem feito muitas associações da palavra TRANSgênicos com outras como: TRANSexual, TRANSvaginal, TRAvesti, homossexual, mudança de sexo, não gostam do seu sexo. Também aparecem outros aspectos como: mistura, diferente/monstro e mutação, que podem indicar a imagem que esses alunos têm dos transgênicos. Por último, nota-se o surgimento de dois outros aspectos, embora com baixa frequência, na possível estrutura das representações sociais dos alunos: economia e risco.

Na condição "logo após a visita à exposição", a análise da estrutura mostrou uma pequena diminuição na frequência da palavra alimentos. Entretanto, após o reagrupamento das evocações, nota-se que esse elemento continua sendo muito importante para os alunos, com uma frequência um pouco maior do que a apresentada pela análise dos conjuntos de palavras referente à condição "antes da visita".

Os conjuntos modificação, genes e biotecnologia seguem a tendência apresentada pela análise da estrutura dessa condição e apresentam frequências maiores do que as correspondentes quando comparadas com a análise dos conjuntos de palavras da condição "antes da visita".

Alguns aspectos que surgiram após o reagrupamento de palavras na primeira condição, também surgem na segunda condição, tais como: agrotóxicos, economia e danos à saúde. Este último, no entanto, pode ter um significado diferente do apresentado na condição "antes da visita". Se, na primeira condição, a expressão danos à saúde poderia estar associada à aplicação dos transgênicos no campo da saúde para reduzir tais danos, na segunda condição essa expressão pode estar se referindo aos danos que os transgênicos podem causar quando aplicados ao campo agroalimentar, enfatizados pela exposição científica.

Há um aumento considerável na frequência apresentada pelo conjunto agricultura, que pode ser explicado pelo viés da exposição científica que privilegiou a aplicação dos transgênicos nesse campo. Nesse sentido, também surgem novos aspectos, tais como: meio ambiente, homem, danos ao meio ambiente, vida e preservação do meio ambiente, que fazem referência à exposição científica pela qual os alunos haviam passado, confirmando a tendência apontada pela análise estrutural dessa condição. Além desses elementos, surge um novo aspecto que não apareceu na análise estrutural: problemas sociais. Embora esse elemento apresente uma frequência muito baixa, isso significa que alguns alunos passaram a considerar esse aspecto em relação aos transgênicos após visitarem a exposição. Desse modo, o elemento risco que havia surgido na análise do reagrupamento da condição anterior, mas que não se remetia a algum tipo de risco específico, desaparece na segunda condição, mas "reaparece" de outras formas: danos ambientais, sanitários e sociais.

Outro aspecto que surge na segunda condição é a referência à informação em relação aos transgênicos, embora também seja pouco evocada. Nesse sentido, o desapare- cimento de elementos como mistura, diferente/monstro e mutação pode estar ligado a uma nova imagem que os alunos construíram acerca dos transgênicos após passarem pela exposição. O mesmo pode ser pensado para o desaparecimento do grupo sexo.

Por último, pode-se notar o surgimento de julgamentos (bom e ruim) em relação aos transgênicos. Embora esses elementos sejam pouco evocados na segunda condição, é importante ressaltar que nas análises (estrutural e de reagrupamento) referentes à condição anterior, esse grupo não tinha emitido nenhum julgamento em relação a esse objeto.

Na condição "um mês após a visita à exposição", o elemento alimentos continua sendo muito importante para esse grupo, apresentando um aumento considerável na sua frequência em relação às duas condições anteriores.

Mais uma vez, os conjuntos de palavras modificação, genes e biotecnologia seguem a tendência apresentada pela análise da estrutura dessa condição e apresentam frequências maiores do que as correspondentes quando comparadas com a análise dos conjuntos de palavras das condições anteriores. Isso também vale para o conjunto ciência e está igualmente relacionado ao surgimento do conjunto tecnologia, já apontado na análise estrutural dessa condição.

Assim como na análise da estrutura da terceira condição apresentada anteriormente, alguns conjuntos de palavras referentes à exposição científica desaparecem (danos ao meio ambiente e preservação do meio ambiente). Ainda assim, outros conjuntos também referentes à exposição se mantêm nessa condição (meio ambiente, homem, vida e problemas sociais).

Também como na análise estrutural apresentada anteriormente, o conjunto remédios apresenta um pequeno aumento na sua frequência em comparação com a condição "depois da visita”, mas não chega perto da frequência apresentada pela condição "antes da visita". Por outro lado, o conjunto saúde passa a ter frequência maior que as das duas condições anteriores. Isso pode significar que, embora a questão da saúde se mantenha importante para os alunos, estes podem ter diminuído a importância dada inicialmente à aplicação dos transgênicos no campo da saúde, em detrimento da importância dada à aplicação dos transgênicos no campo agroalimentar.

Comparando as três condições experimentais, pode-se notar que, apesar da soma da frequência dos conjuntos de palavras corresponderem a um total de evocações muito próximos para as três condições (em torno de 80\%), o número de conjuntos de palavras considerados diminuiu na última condição. Na condição antes da visita e depois da visita foram considerados 27 conjuntos de palavras. Na última condição, um mês após a visita, foram considerados 19 conjuntos de palavras. Isso também confirma os resultados encontrados pela análise estrutural apresentada anteriormente, de que os alunos passaram a compartilhar mais fortemente o vocabulário que eles produziram acerca dos transgênicos.

A análise geral do agrupamento de evocações corrobora a tendência apresentada pela análise geral da estrutura das evocações, e mostra que houve um fortalecimento do "núcleo": alimentos geneticamente modificados. Os novos conjuntos de palavras que surgiram nas condições posteriores podem indicar que a passagem pela exposição científica levou os 
alunos a considerar também os possíveis riscos dos transgênicos, dessa vez não só para a saúde e para o meio ambiente, mas também para a sociedade como um todo.

\section{Discussão}

Moscovici (1978) argumenta que as representações constituem universos de opinião que possuem três dimensões: a informação, a atitude e o campo ou imagem da representação, sendo que a tridimensionalidade não se manifesta em todos os grupos.

Os resultados da primeira condição experimental apresentados anteriormente levam a pensar que a estrutura dos alunos é marcada pela forte presença da dimensão informação (ao menos científica) e pela ausência da dimensão atitude. O campo de imagem desse grupo está ancorado no campo agro-alimentar e da medicina. Para Moscovici (1978), a atitude é a mais frequente das três dimensões e talvez seja a dimensão "geneticamente primordial". Nesse sentido, podese pensar que o conteúdo produzido pelos alunos se refere à informação que estes têm sobre os transgênicos e não a uma representação social propriamente dita.

Ao pensar o processo de construção de uma representação social referente a um objeto social recente, Moscovici (1961/1978) propôs que a formação de uma representação social ocorre por etapas sucessivas, ao longo das quais a informação selecionada e descontextualizada dá lugar a um núcleo imageante. Tal núcleo é uma base estável, sobre a qual a representação vai continuar a se construir. Esse núcleo imageante, chamado de núcleo figurativo, ainda não é o núcleo central, uma vez que a representação ainda não está constituída. Selesses (2005?) aponta que em alguns casos, esse núcleo figurativo se transforma em núcleo central, dando fim ao processo de estruturação da representação. No caso dos alunos, podería-se pensar que alimentos e remédios constituem o núcleo figurativo que permite aos elementos produzidos por esse grupo se organizarem em torno de um núcleo coerente e que sugere um futuro de uma representação social constituída. O emprego de técnicas específicas de confirmação da estrutura representacional, como, por exemplo, o questionamento ou mise en cause (Moliner, 1994) poderia confirmar se tais elementos são centrais ou não para esses alunos.

O fato mais importante a ser considerado a partir desses resultados é que eles confirmam a hipótese de que não se tratava de uma representação já constituída, mas sim, ainda em vias de construção. Portanto, essa pesquisa tratou de verificar o impacto de uma exposição científica sobre transgênicos no processo de formação da representação social desse objeto entre os alunos.

Os resultados obtidos após a visita dos alunos à exposição científica mostraram que ocorreram mudanças nas representações do grupo. Observa-se que os alunos passaram a dar menos importância aos produtos que haviam citado (principalmente em relação aos remédios) e mais importância ao processo pelo qual esses produtos são obtidos (genética e modificados). Observa-se, igualmente, o surgimento de novos elementos no possível sistema periférico desse grupo.
Tais elementos faziam referência ao conteúdo da exposição científica visitada.

Um primeiro aspecto a ser discutido em relação a esses resultados diz respeito aos elementos que estão presentes no primeiro quadrante do grupo investigado. Após a visita à exposição, pode-se observar três movimentos no primeiro quadrante: o aumento da frequência da palavra alimentos; o desaparecimento da palavra remédios; e o surgimento das palavras modificados e genética.

Em relação aos dois primeiros movimentos, pode-se pensar que a exposição científica atuou como uma espécie (guardando as devidas diferenças) de técnica de confirmação do núcleo central. A exposição enfocou a aplicação da engenharia genética no campo da agricultura e não discutiu essa aplicação no campo da medicina. Moliner e Vidal (2003) comentam que, sob certas condições, os elementos centrais de uma representação podem ser sensíveis a informações que os contradizem, principalmente quando a informação contraditória é atribuída a uma fonte de alto status epistêmico, como especialistas, por exemplo. Nesse caso, a exposição científica, tomada como uma fonte de informação especialista, confirmava o elemento alimento e contradizia o elemento remédios. Os resultados dessa confirmação (o aumento da frequência de alimentos) e dessa contradição (o desaparecimento da palavra remédios) reforçam a nossa suposição de que alimentos e remédios não constituíam de fato o núcleo central da representação social de transgênicos desse grupo, a qual ainda está em processo de formação. Esses resultados também mostram que a palavra alimentos tem grande possibilidade de ser um elemento central (embora a "técnica" utilizada não tenha sido de questionar a centralidade desse elemento) e que a palavra remédios, provavelmente, não será um elemento central quando a representação social de transgênicos desses alunos estiver constituída.

O terceiro movimento que ocorreu no primeiro quadrante, o surgimento dos elementos modificados e genética, também mostra um impacto da visita à exposição e confirma o processo de formação dessa representação ainda em curso. Resta saber se esses elementos têm probabilidade de se tornarem centrais.

Um segundo aspecto a ser discutido em relação a esses resultados diz respeito aos outros três quadrantes que formam o possível sistema periférico dessa representação. Nota-se o surgimento de uma série de palavras que não apareciam na estrutura desse grupo antes da visita e que fazem referência à exposição pela qual os alunos haviam passado: plantas e meio ambiente, (no segundo quadrante), natureza, milho, vida, biotecnologia, ser humano e algodão (no quarto quadrante). Algumas dessas palavras são extensões dos elementos que formam o primeiro quadrante nessa segunda situação (alimentos - plantas e milho; genética e modificados - biotecnologia). Porém, o surgimento das outras palavras (meio ambiente, natureza, vida, ser humano) acrescenta outra dimensão ao processo de formação da representação social desses alunos. A questão da intervenção do homem no meio ambiente, na natureza e na própria vida, não aparecia na situação antes da visita, que privilegiava os produtos e processos científicos, sem uma reflexão sobre os mesmos.

Apesar da tipologia proposta por Abric (1998), explicada na introdução deste trabalho, ser empregada para a transfor- 
mação de representações já constituídas (que possuem um núcleo central e uma estrutura definida), pode-se tentar traçar um paralelo em relação ao processo de (trans)formação da representação social de transgênicos dos alunos. Nesse caso, notou-se a integração de elementos no sistema periférico que faziam referência à nova situação, assim como o núcleo central passou a integrar novos elementos sem romper (totalmente) com os elementos centrais existentes.

Esses resultados confirmam e acrescentam novos dados aos resultados achados pelos estudos anteriores sobre o impacto de uma exposição científica nas representações sociais (Carboni, 2005; Martinelli, 2006; Mezzomo \& NascimentoSchulze, 2004). Os resultados anteriores mostravam que a exposição científica tem um papel importante na transformação de representações sociais referentes a objetos de destaque, como o meio ambiente, no sentido de permitir uma maior reflexão sobre os mesmos. Os resultados deste estudo mostram que a exposição tem um papel igualmente importante na própria formação de representações sociais referentes a objetos recentes, mas que são de extrema importância para a sociedade.

Além dos resultados obtidos com a análise das palavras evocadas, a análise do reagrupamento dessas evocações também mostrou que os alunos, além de considerarem os danos ao meio ambiente, passaram a discutir, ainda que em uma proporção menor, os aspectos econômicos, bem como os possíveis problemas sociais que essa tecnologia pode trazer.

Sá (1996), em um estudo que procurava articular a exposição a atividades de divulgação científica pelos meios de comunicação de massa (jornais, revistas e programas de TV) com a estrutura das representações sociais de ciência, verificou que a representação social de ciência dos não consumidores da divulgação científica "se ramifica desde a idealização de um saber acadêmico puro em direção a preocupações cada vez mais concretas” (p. 162). Já a representação dos consumidores da divulgação científica "integra em seu núcleo central, em um nível razoavelmente elevado de abstração e generalidade, a operação em si de construção da ciência ..., seus requisitos éticos ... e sua relação com a sociedade” (p. 162).

Se tentarmos fazer um paralelo com o estudo descrito acima, tomando os transgênicos como um exemplo da discussão sobre o trinômio "ciência, tecnologia e sociedade", pode-se dizer que os alunos na primeira condição, ao destacarem os produtos da engenharia genética (alimentos e remédios), privilegiaram os objetos mais concretos das práticas científicas, valorizando a "dimensão mais utilitária da ciência" (Sá, 1996, p. 163).

Após a visita à exposição, os alunos passaram a dar mais destaque à operação em si de construção da ciência (genética, modificados e biotecnologia) e começaram a considerar as consequências sociais esperadas dessa tecnologia (danos ao meio ambiente, danos à saúde, problemas sociais).

Como já foi dito, o objetivo deste estudo foi verificar o impacto da visita a uma exposição científica na formação das representações sociais dos alunos. Nesse sentido, a terceira condição visou verificar a permanência, em um espaço de tempo (um mês), das mudanças ocorridas após a visita. Entretanto, nesse período, os alunos estudaram os transgênicos em sala de aula com os professores, que também pediram um trabalho de pesquisa sobre o assunto em outras fontes de informação (livros, jornais, revistas, Internet etc). Desse modo, não se pode dizer de fato se a permanência das mudanças se deu apenas pelo impacto da exposição científica. Além disso, os resultados dessa terceira condição mostraram que surgiram novas mudanças na estrutura produzida pelos alunos.

Se, por um lado, não foi possível verificar o impacto (ou a permanência deste) da exposição científica em um prazo maior, por outro lado, essa terceira condição possibilitou verificar o papel da comunicação (em geral) no processo de formação das representações sociais. Além de novas fontes de comunicação, os alunos começaram a discutir sobre esse tema entre eles e com os professores. Moscovici (1978) sempre ressalta a importância da comunicação (em seus diferentes níveis) para a construção das representações.

Os resultados da terceira condição mostram que a palavra alimentos passou a receber ainda mais atenção do que nas duas situações anteriores, o que confirma a hipótese de que esse seja realmente um elemento com grande probabilidade de se tornar um elemento central da representação. Nota-se um aumento na frequência da palavra remédios em relação à segunda condição, mas ela ainda está muito baixa quando comparada com a primeira condição. Isso também pode reforçar a hipótese de que esse elemento não será um elemento central da representação constituída.

Apesar de uma diminuição na frequência da palavra modificados em relação à segunda condição, o aumento da frequência da palavra genética e o deslocamento dos elementos genes e DNA para o primeiro quadrante mostram que os alunos passaram a dar cada vez mais importância à operação de construção da ciência. Apesar da diminuição na frequência, ou mesmo do desaparecimento, de algumas palavras que faziam referência ao conteúdo da exposição, os elementos que surgiram na segunda situação, e que se mantêm na terceira, mostram que os alunos continuam a considerar as esperadas consequências dessa tecnologia, principalmente em relação ao meio ambiente.

Por último, pode-se pensar também que, além de um processo de formação da representação de transgênicos, a própria representação social de ciência desse grupo também passou por uma transformação, que vai ao encontro das representações encontradas para os não consumidores e os consumidores de divulgação científica encontradas por Sá (1996). Assim, os alunos passam de um "entendimento acadêmico básico e tradicional da ciência" para um "entendimento acadêmico moderno da ciência, mais processual, autocrítico e socialmente condicionado” (p. 162).

\section{Considerações Finais}

A participação do público é essencial, como coloca Guivant (2005), "não só para delinear cenários futuros no referente ao desenvolvimento de determinadas inovações tecnológicas, mas também para definir as políticas públicas necessárias para atingir os objetivos que se consideram positivos para a sociedade” (p. 71). Consideramos que a educação (formal e/ou informal) é um passo fundamental para garantir essa participação pública. Nesse processo, a 
divulgação científica tem um lugar de extrema importância, mas precisa ser repensada.

Roqueplo (1974) lança as seguintes perguntas: sendo a função da divulgação, a formação (ou modificação) de representações sociais e, levando em conta as diferentes dimensões destas (atitude, informação, campo de representação), "como se mede a fidelidade de uma representação? É legítimo se privilegiar, como o fazem os 'cientistas', a dimensão 'informativa'? Existem representações mais verdadeiras que outras?” (p. 146). Assim, o autor se pergunta, no caso da divulgação sobre a energia atômica, por exemplo, o que seria mais fiel ou que corresponderia mais à realidade: dar apenas informações neutras (sobre alguns processos) ou informar a população sobre os riscos dessa tecnologia? "Qual é o elemento principal no processo que leva a uma ‘verdadeira' representação social da energia atômica?” (p. 146). Pergunta difícil de ser respondida.

Essa pesquisa mostrou que a exposição científica desempenhou um papel importante na promoção de uma reflexão acerca dos transgênicos por parte dos alunos. Nesse sentido, discordamos dos programas que buscam passar para o público apenas informações neutras, ou ainda, as "maravilhas" da ciência, buscando de fato o apoio deste ao modelo de desenvolvimento linear, no qual mais ciência e tecnologia geram mais desenvolvimento, que gera mais bem-estar social. Pensamos que a divulgação científica tem um papel importante na construção de representações sociais que podem ser usadas como "armas críticas" (Moscovici \& Marková, 2003) e, assim, no despertar da "crítica ativa" da sociedade (Beck, Giddens \& Lash, 1997). Assim, o cidadão "iluminado", não apenas dos saberes científicos, mas, principalmente, dos impactos e riscos que envolvem o seu desenvolvimento e aplicação, poderá participar e decidir os rumos "positivos para a sociedade”. Seria esse então o papel da divulgação científica. Conforme Sá (1996), a prática do consumo da divulgação científica desempenha um papel fundamental na "elevação das dimensões operacionais, éticas e sociais da ciência ao status de cognições centrais” (p. 162).

\section{Referências}

Abric, J.C. (1998). Abordagem estrutural das representações sociais. Em A. S. P. Moreira \& D. C. Oliveira (Orgs.), Estudos interdisciplinares de representação social (pp. 27-38). Goiânia: AB.

Bauer, M. (2003). A popularização da ciência como imunização cultural: a função das representações sociais. Em P. A. Guareschi \& S. Jovchelovitch (Orgs.), Textos em representações sociais (pp. 229-257). Petrópolis: Vozes.

Bauer, M., \& Gaskell, G. (2002). Biotechnology: The making of a global controversy. Cambridge: Cambridge University Press.

Beck, U., Giddens, A., \& Lash, S. (1997). Modernização reflexiva: política, tradição e estética na ordem social moderna. São Paulo: UNESP.

Brasil (2005). Lei $N^{o} 11.105$, de 24 de Março de 2005. Retirado em 18/07/2007, de http://www.planalto.gov.br/ccivil_03/_Ato20042006/2005/Lei/L11105.htm

Bueno, W. (1985). Jornalismo cientifico. Ciência e Cultura, 37, 1420-1427.
Carboni, L. (2005). A influência de uma exposição científica sobre as representações sociais e atitudes relativas ao meio ambiente: um estudo com alunos do ensino médio. Dissertação de Mestrado, Universidade Federal de Santa Catarina, Florianópolis.

Flament, C. (2001). Estrutura e dinâmica das representações sociais. Em D. Jodelet (Org.), As representações sociais (pp. 173186). Rio de Janeiro: UERJ.

Guivant, J. (2002). Heterogeneous and unconventional coalitions around global food risks: Integrating Brazil into the debates. Journal of Environmental Policy \& Planning, 4, 231-245.

Guivant, J. (2005). A governança dos riscos e os desafios para a redefinição da arena pública no Brasil. Em E. Silva, M. Santos \& P. Bacarense (Orgs.), Ciência, tecnologia e sociedade: novos modelos de governança (pp. 47-85). Brasília: CGEE.

Guivant, J. (2006). Transgênicos e percepção pública da ciência no Brasil. Ambiente \& Sociedade, 9, 81-103.

Irwin, A., \& Wynne, B. (1996). Misunderstanding science? The public reconstruction of science and technology. Cambridge: Cambridge University Press.

Jodelet, D. (1986). La representación social: Fenómenos, concepto e teoría. Em S. Moscovici (Org.), Pensamiento y vida social: Vol 2. Psicologia Social (pp. 469-494). Barcelona: Ediciones Paidós.

Jodelet, D. (2001). Representações sociais: um domínio em expansão. Em D. Jodelet (Org.), As representações sociais (pp. 17-44). Rio de Janeiro: UERJ.

Jurdant, B. (1975). La vulgarisation scientifique. La Recherche, 6, 141-155.

Labarrère, M. (2000). A atual legislação de biossegurança no Brasil. Cidadania e Justiça, 4, 202-219.

Lazzarini, M. (2000). Alimentos transgênicos: a precária avaliação dos riscos à saúde. Cidadania e Justiça, 4, 195-201.

Martinelli, V. (2006). Influência dos meios de comunicação em uma exposição científica. Dissertação de Mestrado, Universidade Federal de Santa Catarina, Florianópolis.

Mezzomo, J., \& Nascimento-Schulze, C. (2004). O impacto de uma exposição científica nas representações sociais sobre meio ambiente: um estudo com alunos do ensino médio. Comunicação e Sociedade: Comunicação da Ciência, 6, 151-170.

Moliner, P. (1994). Les méthodes de repérage et d'identification du noyau des représentations sociales. Em C. Guimelli (Org.), Structures et transformations des représentations sociales (pp. 199-232). Neuchâtel: Delachaux et Niestlé.

Moliner, P., \& Vidal, J. (2003). Stéréotype de la catégorie et noyau de la représentation sociale. Revue Internationale de Psychologie Sociale, 1, 157-175.

Moscovici, S. (1978). A representação social da psicanálise (A. Cabral, Trad.). Rio de Janeiro: Zahar. (Trabalho original publicado em 1961)

Moscovici, S., \& Marková, I. (2003). Idéias e seu desenvolvimento - um diálogo entre Serge Moscovici e Ivana Marková. Em S. Moscovici. (Org.), Representações sociais: investigações em psicologia social (pp. 305-387). Petrópolis: Vozes.

Nascimento-Schulze, C. (2007). Science et société: Imposer, motiver ou persuader? Diogène, 217, 166-176.

Nascimento-Schulze, C. M., \& Camargo, B. V. (2000). Psicologia social, representações sociais e métodos. Temas em Psicologia da SBP, 8, 287-299. 
Nunes, T. (2005). A influência da música sobre as representações sociais de meio ambiente no contexto de uma exposição científica. Dissertação de Mestrado, Universidade Federal de Santa Catarina, Florianópolis.

Porto, M. (2005). Riscos, incertezas e vulnerabilidades: transgênicos e os desafios para a ciência e a governaça. Política \& Sociedade, 7, 77-103.

Roqueplo, P. (1974). Le partage du savoir: Science, culture, vulgarisation. Paris: Éditions du Seuil.

Sá, C.P. (1996). Núcleo central das representações sociais. Petrópolis: Vozes.

Salesses, L. (2005). Rôle du niveau de connaissance dans le processus de structuration d'une représentation sociale. Les Cahiers Internationaux de Psychologie Sociale, 66, 25-42.

Silva, V., \& Amaral, A. (2004). Segurança alimentar, comércio internacional e segurança sanitária. Informações Econômicas, 34, $38-45$.
Silva, C., \& Melo, L. (2001). Livro Verde. Ciência, tecnologia e inovação: desafio para a sociedade brasileira. Brasília: Ministério da Ciência e da Tecnologia / Academia Brasileira de Ciências.

Vergès, P. (1999). Ensemble de programmes permettant l'analyse des évocations. Manuel d'utilisateur. Aix en Provence: Université Aix en Provence.
Recebido em 24.04 .08

Primeira decisão editorial em 27.01.09

Versão final em 12.02.09

Aceito em 26.04.09 